\title{
A construção de currículos narrativos mediados pelas tecnologias: um olhar para a formação de professores e as narrativas digitais de aprendizagem ${ }^{1}$
}

\section{The construction of narrative curricula mediated by technologies: a look at teacher training and digital learning narratives}

\author{
Alessandra Rodrigues* \\ Maria Elizabeth Bianconcini de Almeida**
}

\begin{abstract}
RESUMO
Este artigo apresenta um estudo sobre a utilização de narrativas digitais de aprendizagem em contexto de formação de professores. Como dados empíricos, são analisados discursos de mestrandos(as) produzidos em uma disciplina de um Programa de Pós-Graduação em Ensino de Ciências (Mestrado Profissional) de uma universidade pública brasileira, buscando indícios de construção do currículo narrativo a partir da produção e veiculação de narrativas digitais de aprendizagem elaboradas como atividade curricular. A recolha de dados compreendeu o acompanhamento da disciplina (estruturada por meio de encontros presenciais e atividades realizadas em ambiente virtual) e a realização de dois grupos focais com os sujeitos da investigação. As análises dos dados tiveram como inspiração a Análise de Discurso e utilizaram o software NVivo como suporte para a composição do corpus. $\mathrm{O}$ estudo indica as narrativas digitais de aprendizagem como um dos caminhos para a construção do currículo narrativo, proposto por Ivor Goodson, uma vez que são espaços profícuos para o reconhecimento da experiência dos
\end{abstract}

1 A pesquisa de que trata este artigo foi financiada pelo Conselho Nacional de Desenvolvimento Científico e Tecnológico (CNPq).

"Universidade Federal de Itajubá. Itajubá, Minas Gerais, Brasil. E-mail: alessandrarodrigues@ unifei.edu.br - https://orcid.org/0000-0001-5161-9792

${ }^{* * *}$ Pontifícia Universidade Católica de São Paulo, São Paulo, Brasil. E-mail: bbethalmeida@ gmail.com - https://orcid.org/0000-0001-5793-2878 
sujeitos em articulação com os conteúdos curriculares incitando a ecologia de saberes. Assim, propõe que o uso de narrativas digitais de aprendizagem pela perspectiva do currículo narrativo pode ser entendido como uma possibilidade didático-metodológica para a formação de professores.

Palavras-chave: Narrativas Digitais. Formação Docente. Currículo Narrativo. Tecnologias Digitais de Informação e Comunicação (TDIC).

\begin{abstract}
This article presents a study on the use of digital storytelling of learning in the teacher education context. As empirical data, speeches of master's students produced in a Postgraduate Program in Science Teaching (Professional Master's Degree) discipline of a Brazilian public university were analyzed, looking for signs of construction of the narrative curriculum from the production and placement of digital learning narratives developed as a curricular activity. Data collection included the course follow-up (structured through face-to-face meetings and activities carried out in a virtual environment) and two focus groups with the research subjects. The data analyzes were inspired by French Speech Analysis and used the NVivo software as for the corpus composition support. The study indicates the digital storytelling of learning as one of the ways for the built, proposed by Ivor Goodson, since they are valuable spaces for the subjects' experience recognition in articulation with the curricular contents, inciting the ecology of knowledge. Thus, it proposes that the use of digital storytelling for learning from the perspective of the narrative curriculum can be understood as a didactic-methodological possibility in the teacher's training.

Keywords: Digital Storytelling. Teacher Training. Narrative Curriculum. Information and Communication Technology (ICT).
\end{abstract}

\title{
Apresentação
}

Este artigo explora o conceito de currículo narrativo, proposto por Goodson (2007a; 2007b; 2010), apresentando uma possibilidade de realização desse currículo em contextos educacionais por meio da construção de narrativas digitais de aprendizagem de professores participantes de um processo formativo.

Entendemos o currículo narrativo como um entrelugar capaz de estimular a construção de uma sociedade mais crítica e mais justa - tanto social quanto cognitivamente. A opção por essa abordagem do currículo como um entrelugar se dá, especialmente, pelas próprias características desse currículo que o fazem ser 
construído nas interfaces e integrações possíveis entre os conteúdos curriculares prescritos e o contexto social dos sujeitos - onde as epistemologias podem conviver numa ecologia (SANTOS, 2007; 2010a; 2010b) em que a hierarquização dos conhecimentos (e das formas de conhecer) não se dê a priori, mas no encontro e no diálogo entre lógicas, saberes e fazeres respeitando as trajetórias curriculares e fazendo delas o próprio caminho para a construção de um currículo narrativo. A escolha do termo fundamenta-se também na ideia de Goodson (2010) sobre as narrativas serem ferramentas potencialmente importantes de aprendizagem com implicações substanciais para as ações subsequentes dos sujeitos. O currículo narrativo seria, então, um "entrelugar" teórico-conceitual que abrange outros elementos-lugares de aprendizagem: as narrativas, a experiência, a aprendizagem narrativa e o capital narrativo. Como entrelugar, o currículo narrativo não é facilmente reconhecível, tampouco replicável ou estático em distintos contextos. Ao contrário, é moldável, adapta-se aos contextos e suas especificidades bem como às experiências dos sujeitos aprendentes.

$\mathrm{Na}$ exploração da materialidade do conceito e de sua possível realização em contextos educacionais tendo como elemento central a produção de narrativas digitais, apresentaremos e analisaremos recortes discursivos tanto de narrativas digitais de aprendizagem (NDA) produzidas por mestrandos(as) quanto de falas desses sujeitos em grupos focais - conforme explicitaremos no tópico dedicado aos aspectos metodológicos do estudo.

\section{O currículo narrativo como entrelugar: produção de conhecimentos e subjetividades}

A construção de um currículo, na formação de professores, que propicie a reflexão emancipadora e que reconheça os sujeitos e seus conhecimentos requer, primeiro, a abertura ao diálogo, à escuta (FREIRE, 1987). É preciso parar para ver, ouvir, ler e permitir o acontecimento da experiência autêntica, genuína, que atravessa o sujeito, toca-o, provoca a reflexão sobre si mesmo situado no mundo e o (re)constitui (HEIDEGGER, 2003; LARROSA, 2002, 2011).

Nesse sentido, Bruner (2001, p. 46) aponta que "É apenas no modo narrativo que um indivíduo pode construir uma identidade e encontrar um lugar em sua cultura". Desde essa perspectiva, a narrativa coloca-se como uma possibilidade real de construção deste currículo a que nos referimos, "[...] como um modo de pensamento, como uma estrutura para a organização de nosso conhecimento e como um veículo no processo de educação" (BRUNER, 
2001, p. 117). Constituindo-se narrativamente, o currículo da formação de professores pode favorecer o reconhecimento dos sujeitos e de suas experiências, incentivando a tomada de consciência, a (co)produção de sentidos, a autoria e, em última instância, a reflexão emancipadora.

Assim, a narrativa pode contribuir para reduzir o abismo entre a prescrição curricular e as experiências sociais dos sujeitos que vivenciam o currículo; uma vez que possibilita ao sujeito dizer a sua palavra sobre si e sobre o mundo (em diálogo com este), definindo seu lugar na história como ser consciente de sua historicidade e de sua ação. Trata-se, assim, de um currículo que se constrói pela via de uma ecologia de saberes (SANTOS, 2007; 2010a; 2010b) que reconhece e se baseia na "[...] pluralidade de conhecimentos heterógenos (sendo um deles a ciência moderna) e em interações sustentáveis e dinâmicas entre eles sem comprometer a sua autonomia" (SANTOS, 2010a, p. 53). Assim, o currículo é compreendido tanto como uma construção cultural e social quanto como um conceito abstrato.

A partir dessa compreensão, chegamos ao que Goodson (2007a, p. 251) postula como sendo o "currículo narrativo", ou seja, o "[...] currículo que se comprometa com as missões, paixões e propósitos que as pessoas articulam em suas vidas. [...] um currículo para o empoderamento" que contribua para que os sujeitos assumam sua posição de autores e construam também, pelo narrarse, uma consciência histórica. Em outras palavras, seria possível afirmar que o currículo narrativo teria como eixo central a experiência dos sujeitos.

Nesse sentido, o potencial educacional e formativo das narrativas e sua importância na construção do currículo como experiência e identidade narrativa parecem inequívocos, uma vez que envolvem "[...] o saber, a identidade e a racionalidade sobre como as pessoas constroem o conhecimento do mundo ao seu redor, a compreensão de si mesmas e a interlocução com as outras pessoas" (ALMEIDA; VALENTE, 2012, p. 63). Em consonância com essas proposições e no esforço de aprofundamento conceitual sobre o currículo narrativo, proposto por Goodson (2007a, 2010), é possível compreendê-lo como um currículo que se estrutura enquanto prática discursiva e de significação. Um currículo voltado a privilegiar as aprendizagens sem hierarquizá-las, mas colocando-as em relação, a partir das narrativas de aprendizagem, e tendo a "aprendizagem narrativa" como elemento estruturante. Essa aprendizagem, para Goodson (2007a), desenvolvese considerando o trajeto, a busca e o sonho dos sujeitos para a construção e manutenção de uma narrativa de identidade ao longo da vida.

Para elaborar o conceito de "capital narrativo", também basilar à compreensão da ideia de currículo narrativo, Goodson (2007a; 2007b) parte das teorizações de Bourdieu e Passeron acerca do capital cultural e seus efeitos 
de reprodução social na escola. O autor propõe pensarmos a respeito de um novo tipo de capital - o narrativo - capaz de interromper a transmissão regular de privilégios na medida em que reconhece e contempla grupos diferentes e as formas como eles teorizam, projetam e historiam suas vidas e orientações. Nessa direção, podemos aproximar as ideias de Goodson à de ecologia de saberes, proposta por Boaventura de Sousa Santos (2007; 2010a; 2010b).

Compreendemos que considerar a aprendizagem narrativa e o capital narrativo no currículo seja um exercício de escuta e de compartilhamento; de valorização, compreensão e posterior teorização, pelos sujeitos curriculantes, do direito de historiar as experiências vividas, de construir e negociar significados projetando futuros possíveis. Nessa direção, as narrativas curriculares têm o papel de atuar como promotoras de autoria, empoderamento e emancipação do sujeito a partir da conscientização de seu lugar na cultura, na história e na sociedade.

Ainda que, em seus estudos, Goodson (2013a; 2010; 2007a; 2007b; 2004) trate de histórias de vida, suas contribuições são importantes para pensarmos a utilização curricular das narrativas digitais de aprendizagem (RODRIGUES, 2019a, 2017; SANTOS; RODRIGUES; REZENDE JUNIOR, 2018; RODRIGUES; ALMEIDA; VALENTE, 2017; ALMEIDA; VALENTE, 2012) na educação formal com vistas à construção de um currículo narrativo que consiga aliar aos conteúdos formais a experiência de aprendizagem e de vida dos sujeitos. Um currículo que seja coerente para os sujeitos porque está vinculado às suas experiências e porque abre espaço para suas vozes, mas também porque considera elementos do contexto histórico no qual se insere e é construído. Um contexto que, por sua vez, reflete padrões anteriores de conflito e de poder em um processo pelo qual a construção do currículo "inventa a tradição" (GOODSON, 2013b, p. 27).

Desde essa perspectiva, consideramos neste texto a potencialização da construção de narrativas com a mediação das Tecnologias Digitais de Informação e Comunicação (TDIC) e seu impacto no currículo narrativo e na formação docente (RODRIGUES; ALMEIDA, 2017; MADDALENA; D'ÁVILA; SANTOS, 2018; RODRIGUES, 2019a; 2019b). Salientamos, nesse tipo de narrativa, os elementos que lhe constituem e dão especificidade - apresentados por Paul (2007, p. 122) como sendo “[...] mídia, ação, relacionamento, contexto e comunicação. A maior parte desses elementos é herdada de outras mídias, mas uma combinação exclusiva de elementos no ambiente digital permite novas possibilidades narrativas". As múltiplas linguagens (visual, escrita, sonora, icônica etc.) que se articulam e se entrelaçam nesse tipo de narrativa, além das possibilidades de representação hiper e multimidiática e de leitura não linear (características das NDA), podem ser ferramentas educativas potencialmente 
transformadoras da aprendizagem e da relação docente-discente nos processos de ensinar e de aprender mediados pelas TDIC, desde que exploradas como mais do que simples aparatos tecnológicos.

Neste texto, tomamos a seguinte definição de narrativas digitais de aprendizagem:

[...] narrativas cujo enfoque temático centra-se no processo formativo dos sujeitos narradores (ainda que tenha diferentes recortes contextuais e temporais), são construídas com uso de tecnologias digitais de informação e comunicação, utilizam recursos multimodais de linguagem em sua constituição e se apresentam por meio de suportes multi ou hipermidiáticos (RODRIGUES, 2017, p. 128).

Entendemos que a representação, nas narrativas digitais de aprendizagem, do processo formativo dos sujeitos com e por meio das TDIC fortalece o uso e a apropriação das tecnologias, que funcionam como parceiras intelectuais dos sujeitos estimulando a criatividade, o pensamento crítico e a aprendizagem narrativa. Nessa direção, conforme aponta Rodrigues (2019c, p. 105),

[...] é preciso jogar luz sobre os efeitos da multiplicidade de formas pelas quais é possível construir narrativas com recursos digitais e torná-las públicas também por esses recursos. Outra possibilidade que se amplia em função da digitalidade é a construção de narrativas em coautoria e em redes. Além das construções colaborativas, as TDIC ainda facilitam consideravelmente o trabalho de revisão e alteração permanente dos elementos da história num movimento de "fazer/refazer" que vem promovendo alterações nas funções de autor e leitor quando atravessadas pelas tecnologias.

Vistas por esse prisma, na formação docente, as narrativas digitais podem ser, elas próprias, espaços de significação e recontextualização do vivido e de construção do currículo num movimento criativo e crítico-reflexivo que busca uma educação de qualidade, articulada com a cultura de seu tempo e as lutas sociais que se materializam no cotidiano da escola; mas também uma educação com alma, na qual sentimentos, emoções, desejos e sonhos têm lugar como construtores/articuladores do conhecimento (FREIRE, 1996). 


\section{Aspectos Metodológicos}

A investigação da qual este artigo é originário teve como lócus uma disciplina semipresencial de um Programa de Pós-Graduação em Ensino de Ciências - Mestrado Profissional - de uma universidade pública brasileira. Nessa disciplina de 60 horas-aula em que foram realizados quatro encontros presenciais de 4 horas cada, os sujeitos produziram e publicizaram suas narrativas digitais de aprendizagem. Os recortes discursivos analisados neste estudo foram coletados em dois contextos discursivos dos quais participaram os 16 sujeitos de pesquisa, que constam neste texto com nomes fictícios. Cabe salientar que todos os procedimentos éticos da pesquisa científica foram cumpridos e aprovados pelo Comitê de Ética.

Os dados analisados neste artigo advêm de um percurso metodológico que incluiu o acompanhamento da produção e divulgação de versões parciais das narrativas digitais postadas e comentadas durante um semestre letivo em um grupo secreto ${ }^{2}$ criado para a disciplina na rede social Facebook e pela realização de dois grupos focais com os sujeitos. Os grupos focais foram realizados simultaneamente, ao final da disciplina, tendo oito sujeitos em cada grupo, seguindo as determinações de Gatti (2012) para esse procedimento de coleta de dados. As análises aqui apresentadas foram realizadas após o encerramento da disciplina e buscam articular discursos produzidos nesses contextos enunciativos (grupos focais) e nas narrativas digitais de aprendizagem dos sujeitos.

O conjunto de dados constituído ao longo desse percurso foi organizado com auxílio do software NVivo (versão NVivo10). Para compor o corpus, foram identificados os recortes discursivos associados a diferentes temáticas (denominadas no software como "nós") e esses recortes foram vinculados aos nós criados no software. Assim, o conjunto final de recortes originado dessas associações constituiu o corpus por meio de um trabalho que vinculou "um só discurso a um conjunto de textos" - possibilidade considerada a partir de Maingueneau (2015).

Neste texto, delimitamos a apresentação dos dados referentes à temática da construção do currículo narrativo por meio da produção e publicização de narrativas digitais de aprendizagem. Cabe informar ainda que as análises

2 Esta rede social permite a criação de grupos secretos, cujo acesso às publicações e a permissão para postagens são restritos aos integrantes cadastrados no grupo. Assim, o material disponibilizado é facilmente acessado pela rede social, mas não fica público. 
tiveram inspiração na análise de discurso de linha francesa (PÊCHEUX, 2010; ORLANDI, 2013; MAINGUENEAU, 2015). Assim, o discurso é entendido nesta investigação "[...] como uma das instâncias em que a materialidade ideológica se concretiza, isto é, um dos aspectos materiais da 'existência material' das ideologias" (BRANDÃO, 2012, p. 46). O discurso funciona nas e pelas instituições e deriva de um lugar, de uma posição político-ideológica ocupada pelo sujeito em uma formação social dada. Esse lugar altera o discurso, cuja análise, nessa perspectiva, nunca se pretende total, final, determinante; mas ao contrário, fornece nuances de interpretação e efeitos de sentido possíveis. É uma análise contextual, localizada espacial e temporalmente. Nessa direção, as análises pretendem " $[\ldots . .$.$] colocar o dito em relação ao não dito, o que o sujeito$ diz em um lugar com o que é dito em outro lugar, o que é dito de um modo com o que é dito de outro, procurando ouvir, naquilo que o sujeito diz, aquilo que ele não diz, mas que constitui igualmente os sentidos de suas palavras" (ORLANDI, 2013, p. 59). Assim, pretendemos “[...] apreender o discurso como entrecruzamento de um texto e de um lugar social [...]" ocupado por seu produtor (MAINGUENEAU, 2008, p. 143), sem, contudo, ter a pretensão de revelar a verdade final, a essência do discurso ou mesmo da experiência.

\section{Experiências e aprendizagens de um currículo narrativo mediado pelas TDIC: resultados da pesquisa}

Iniciamos a apresentação e discussão dos dados de pesquisa chamando atenção para os apontamentos de Goodson (2007a) acerca do fato de o currículo narrativo dialogar com "[...] as missões, paixões e propósitos" que os sujeitos articulam em suas vidas. $O$ recorte a seguir acena para o percurso curricular de uma mestranda articulado, pela narrativa, à sua experiência de vida em um sentido que extrapola a formação docente. 
FIGURA 1 - RECORTE 1 DA NARRATIVA DIGITAL DE LUANA

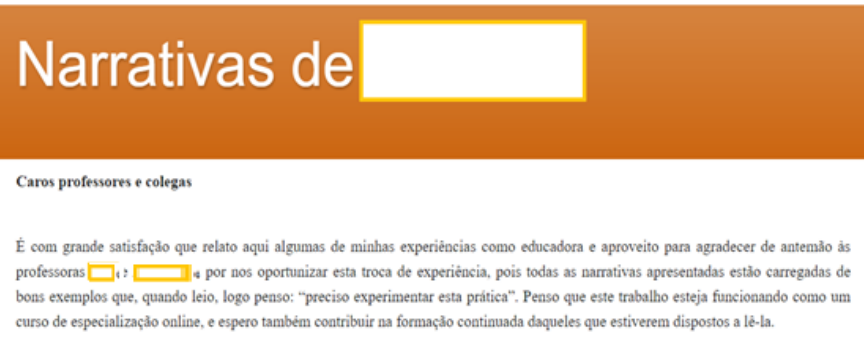

FONTE: Dados de pesquisa.

O discurso de Luana permite interpretações relacionadas ao percurso curricular. Quando relata: "Penso que este trabalho esteja funcionando como um curso de especialização online", a mestranda associa a produção das narrativas digitais de aprendizagem a uma outra formação (extra). Isso pode estar relacionado ao crescimento pessoal proporcionado pela escritura de si, pela exposição dialógica das produções no ambiente virtual da disciplina e pelo acesso às narrativas dos colegas numa experiência curricular narrativa na qual a participação de todos (docentes e discentes) foi responsável pela construção de um contexto virtual de trocas, diálogos e colaboração. Esse movimento pode ser indiciário de um currículo narrativo (GOODSON, 2007a, 2010) que permite e fomenta a ecologia de saberes proposta por Santos (2007, 2010a, 2010b). Na intersecção de todos esses elementos, foi sendo construída uma experiência curricular pela qual os sujeitos exercitaram desenvolver, como aponta Goodson (2007a, p. 251), suas "[...] capacidades para definir e narrar [como professores] seus propósitos de vida e missões". Cabe dizer ainda que as características de fluidez, facilidade de edição e compartilhamento, possibilidade de leitura não linear e multimodalidade de linguagens - próprias das TDIC - podem ter contribuído para essa percepção de Luana, já que as narrativas tradicionais tendem a ser mais estanques, muitas vezes mais extensas e, por isso, têm maior dificuldade em impactar diferentes tipos de leitores. Essas características também facilitaram a inserção das NDA na construção curricular como elementos importantes para a construção coletiva e colaborativa de conhecimentos.

Em outro recorte discursivo de sua narrativa digital de aprendizagem, Luana nos permite acessar parte de sua história pessoal e, a partir daí, podemos compreender melhor sua percepção acerca da experiência. Luana inicia sua narrativa digital afirmando: "Como não poderia ser diferente, vou começar contando a história sobre como tudo começou..." e "Acredito que já nasci 
professora [...] Minha professora, Dona Marli, muito competente, rígida, mas ao mesmo tempo extremamente carinhosa, foi minha inspiração". Na primeira enunciação, Luana mostra a impossibilidade de falar de suas práticas como docente sem situar-se, antes, num contexto social e histórico. Ao enunciar "Como não poderia ser diferente", inscreve, no discurso, as múltiplas posições-sujeito (PÊCHEUX, 2010; BRANDÃO, 2012) que a constituem desde antes do tempo narrado nessa experiência do mestrado articulando passado e presente - o que, de certa forma, contribui para a estruturação de seu percurso curricular enquanto uma prática discursiva e de significação historicamente situada (GOODSON, $2007 \mathrm{a}$; 2010) que articula o caráter temporal de sua identidade narrativa, conforme postula Ricoeur (1994). Nessa articulação, Luana mobiliza, na narrativa digital, a tridimensionalidade do tempo narrativo, pelo qual passado, presente e futuro estão imbricados. Essa tridimensionalidade pode ser facilitada pelos recursos tecnológicos, como veremos mais adiante.

$\mathrm{Na}$ segunda enunciação, há um indicativo da construção de um saber de si que se faz pela escritura de si. Esse saber de si provocado pelo narrar-se parece fortemente vinculado à ideia de uma "[...] aprendizagem narrativa que se desenvolve na elaboração e na manutenção continuada de uma narrativa de vida ou de identidade" (GOODSON, 2007a, p. 248). Quando se remete ao fato de já ter nascido professora e às qualidades da primeira professora que teve ("competente", "rígida", "carinhosa"), Luana inscreve-se numa formação ideológica pela memória discursiva (ORLANDI, 2013) que pode remeter à sua concepção de docência, por um lado, como vocação ("já nasci professora"); por outro, como competência desenvolvida e como equilíbrio entre rigidez e afeto. Em ambos os casos, o discurso pode nos indicar a própria identidade docente de Luana (inspirada na primeira professora), ainda que, na narrativa, ela possa não ter conscientemente escolhido gerar esses efeitos de sentido (BRANDÃO, 2012; ORLANDI, 2013, MAINGUENEAU, 2008).

Nessa direção, tanto a aprendizagem narrativa quanto o currículo narrativo estariam diretamente ligados à assunção da autoria pelos sujeitos desse currículo (RODRIGUES, 2017) - os quais, mobilizando o "capital narrativo" (GOODSON, 2007a; 2007b) formado pelo repertório de cada um dos mestrandos e de todos numa relação dialógica, reconhecem-se e assumem seus percursos curriculares gerando uma aprendizagem crítico-reflexiva e situada. Tal perspectiva analítica sustenta-se em vários recortes discursivos advindos do contexto enunciativo de um dos grupos focais, dentre os quais destacamos os das mestrandas Helena e Mel: 
Helena: No texto mesmo a gente conseguia encontrar as caracteristicas das pessoas, que é muito diferente de, por exemplo, vamos supor, nos projetos de pesquisa, quantas vezes eu não escutei a [nome de uma professora] falar assim: "Eu não te vi no texto. O texto está muito bem elaborado, muito bem escrito, mas eu não te vi aqui" (grifos nossos).

Mel: Eu começo a ler a narrativa do outro e começo a escutar o outro falando. E você começa a pensar o outro. Então você enxerga o outro mesmo! [...] É uma coisa assim, cada um faz o seu, não é um trabalho que o de todo mundo fica meio igual. Eu, por exemplo, sou uma pessoa agitada, elétrica e a minha narrativa eu fiz no Prezi e ela é cheia de movimento (grifos nossos).

A percepção do outro, em sua função-autor na narrativa digital, aponta para o desenvolvimento do pensamento narrativo (BRUNER, 1997; 2004) pelos sujeitos à medida que as narrativas se desenvolvem e mostram a inseparabilidade de personagem, ambiente e ação, assim como a localização espaço-temporal da experiência e suas vicissitudes. Da mesma maneira, provoca no sujeito-leitor o exercício de "pensar o outro" (como enunciou $\mathrm{Mel}$ ), considerando também os seus saberes e fazeres (seu capital narrativo) como fontes de conhecimento e aprendizagem - o que se aproxima da ecologia de saberes proposta por Boaventura Santos $(2007$; 2010a) e pode ajudar a combater o elitismo sócio-cognitivo num movimento dialético de pensar o outro e pensar com/por meio do outro.

Ainda sobre esses recortes, destacamos a associação discursiva possível entre o não reconhecimento dos sujeitos em sua produção e a não assunção da autoria em trabalhos tradicionais. Ao desvincularem as narrativas digitais de aprendizagem de produções em que não é possível identificar o autor e reconhecer-lhe a autoria, as mestrandas inscrevem-se em uma formação ideológica (PÊCHEUX, 2010; ORLANDI, 2013) de crítica a essas produções (muitas vezes insossas e cumpridas como meros requisitos formais) e sugerem a singularidade da experiência, conforme ela é proposta por Heidegger (2003) e Larrosa $(2002,2011)$, ao falarem sobre as narrativas como elementos de construção curricular e não apenas como conclusão de um trabalho disciplinar. Assim, nos permitem pensar sobre a importância de que os currículos da formação docente fortaleçam e favoreçam a autoria dos sujeitos abrindo espaços para construções cognitivas e saberes comumente deixados à margem nas hierarquias curriculares tradicionais. 
O convite e a abertura à manifestação da heterogeneidade constitutiva de cada mestrando(a) e a percepção dos sujeitos acerca do acolhimento pelo currículo dessas subjetividades e de suas construções cognitivas em diálogo com a alteridade, através das narrativas digitais, podem ser uma forma de promover o currículo narrativo e parecem potencializadas pelos recursos próprios das TDIC, como sugere Mel ao afirmar: "Eu, por exemplo, sou uma pessoa agitada, elétrica e a minha narrativa eu fiz no Prezi e ela é cheia de movimento". Nas narrativas tradicionais, nem sempre é possível, somente pela escrita, representar os sujeitos-autores. A narrativa digital, pelas características das TDIC, é repleta de movimento, em uma dinâmica que é potencializada por meio de múltiplas linguagens e semioses. Entendemos que isso seja também um ganho para a construção de um currículo narrativo mediado pelas TDIC.

As possibilidades discursivo-narrativas abertas pela mediação das TDIC podem ser, nesse sentido, um chamado à fruição, ao entregar-se à escritura (RODRIGUES, 2017) e à experiência de narrar-se e de desenvolver o pensamento narrativo (BRUNER, 1997; 2004) sem amarras disciplinares - o que propicia condições para que o currículo narrativo também possa se desenvolver. Clara nos remete a uma nova dinâmica de aprendizagem, mediada pelas TDIC, em que a razão instrumental e a razão crítico-reflexiva são complementares:

Clara: Acho que a narrativa nos obrigou ainda mais a buscar, escrever, ler no computador por causa das narrativas dos colegas... Acho que isso nos fez crescer nesse âmbito da questão da tecnologia. A narrativa eu acho que foi o elo entre colegas e a sala do mestrado (grifos nossos).

A fala de Clara, corroborada por outros(as) mestrandos(as), nos permite inferir que, com a produção das narrativas digitais, eles percebem que a mídia em si não despersonaliza e tampouco supera o professor, mas pode contribuir para que se instale um processo mais dialógico de aprendizagem no qual têm vez e voz todos os sujeitos do currículo ("A narrativa foi o elo entre os colegas e a sala do mestrado"). Apesar de utilizar a expressão "nos obrigou" para se referir aos avanços proporcionados pelas NDA relativamente ao domínio das TDIC ("nos fez crescer nesse âmbito da questão da tecnologia"), o discurso de Clara produz efeitos de sentido que escapam à memória discursiva tradicional sobre a obrigação como algo negativo e chato. As NDA obrigaram a "buscar, escrever, ler" e "fizeram crescer" - o que são ações associadas a efeitos de sentido positivos no discurso. Esse deslize dos sentidos pode nos ajudar a perceber que, de fato, a mestranda não se sentiu obrigada a realizar as ações, 
mas estimulada a fazê-lo em função da dinâmica de aprendizagem instaurada pela produção/veiculação das NDA. Trata-se, então, de um currículo aberto ao falar de si e posicionar-se diante do outro que é carregado de sentidos possíveis que se desprendem dos sujeitos e podem ser negociados e renegociados no diálogo com o outro. Em outras palavras, um currículo que seja potencialmente importante, que amplie o capital narrativo (GOODSON, 2007a, 2007b) e que tenha implicações substanciais para as ações subsequentes dos sujeitos, conforme propõe Goodson (2010).

O espaço aberto pela elaboração e compartilhamento das narrativas digitais para a expressão das vozes dos colegas traz para o currículo a possibilidade de diálogo entre saberes e epistemologias não institucionalizados numa dinâmica de reconhecimento do outro e de si como sujeitos de conhecimentos que podem produzir juntos um novo saber. Essa ecologia (SANTOS, 2010a; 2010b) na qual podem conviver (sem hierarquizações feitas a priori) diferentes conhecimentos pode ser facilitadora tanto dos processos crítico-reflexivos e de reconhecimento de si quanto do empoderamento dos sujeitos do currículo na medida em que eles veem reconhecidas, pelos outros, suas experiências e seus conhecimentos em um processo de autoria e fruição que entrelaça experiência e narrativa (ALMEIDA, 2019). Esse movimento dialógico de construção de sentidos e de elaboração do conhecimento considerando as múltiplas vozes que constituem nossos discursos e que constroem nossa experiência curricular parece ter sido percebido por Dalva:

Dalva: Uma coisa que eu queria falar e que aconteceu algumas vezes é que nós utilizamos as falas dos nossos colegas nas nossas narrativas. E eu queria comentar isso, de como é importante você ver aquilo que você fala na voz do outro. E como que de uma certa forma você reflete novamente, você passa a pensar naquilo que você fala de uma outra forma (grifos nossos).

A dinamicidade dos recursos digitais, bem como a que se estabeleceu no grupo secreto criado na rede social, permitiu que os sujeitos tivessem acesso a versões parciais das narrativas dos(as) colegas e publicizassem suas narrativas (como obras abertas e ainda em construção) - o que gerou movimentos críticoreflexivos que alteraram as narrativas em fase de elaboração. Entendemos que esse movimento também altera o currículo e a formação e pode ser facilitado exatamente pelo " $[\ldots]$ ponto comum do qual resultam as outras características das novas mídias [que] é a intersecção de duas áreas até diferentes, os meios 
de comunicação e os computadores" (MARTINO, 2015, p. 211). Assim, as narrativas digitais contribuem para a instauração de uma dinâmica que, se bem explorada, pode contribuir para construções curriculares mais abertas, dialógicas e horizontais nas quais os diversos atores do curículo colaboram ativamente para a formação individual e coletiva dos sujeitos.

Além disso, ao ver-se na narrativa do outro e também em sua própria narrativa (como outro de si), o sujeito se surpreende e se reinventa num processo que pode levá-lo à singularidade da experiência de aprender narrativamente. Parece ter sido esse o percurso curricular de Nina, que em um primeiro recorte discursivo faz referência a sentimentos de "decepção", "desespero" e "angústia" associados à ideia de narrar práticas docentes. Esses sentimentos parecem estar diretamente ligados à memória discursiva (ORLANDI, 2013) acerca do que sejam essas práticas e de como elas só poderiam ser realizadas em sala de aula.

Agregando as formas pelas quais as pessoas teorizam, projetam e historiam suas vidas, o capital narrativo (GOODSON, 2007a, 2007b) dos sujeitos trazido para as narrativas digitais de aprendizagem parece ter sido basilar para a construção dessas narrativas e em grande parte responsável também pelo desenvolvimento de um currículo no qual mestrandos(as) puderam perceber a própria continuidade de seus percursos formativos, como indica o recorte discursivo de Clara:

Clara: Eu entendi que eu não sou a mesma de quando eu comecei a dar aulas. Que sou professora para contribuir com a formação de pessoas críticas, pensantes, reflexivas e não para formar biólogos [...] e foi ai que eu levei as narrativas pra eles [alunos do $1^{\circ}$ ano] (grifos nossos).

No recorte discursivo a seguir, a mestranda passa a identificar-se como uma profissional mais atenta aos diferentes sujeitos que compõem seu universo de trabalho e formação e, por isso, como uma professora mais reflexiva:

Clara: A narrativa me fez ficar mais atenta à fala dos alunos, dos colegas [do mestrado], dos colegas de dentro da minha escola, da escola em si. A partir da narrativa, sou uma professora mais reflexiva, que olha o aluno como um todo, que olha o aluno como pessoa. Antes de ser aluno, ele é uma pessoa (grifos nossos). 
Ao renovar o olhar para seus alunos, Clara ressignifica a experiência vivida no mestrado e a recontextualiza como possibilidade de construção de um currículo narrativo também na escola em que trabalha, preocupando-se não somente com o futuro econômico de seus alunos, mas especialmente com o "[...] caminho para um novo futuro social" em que o currículo possa ser construído "[...] como identidade narrativa" propiciando a "aprendizagem narrativa de gerenciamento da vida" (GOODSON, 2007a, p. 242). Dessa forma, a mestranda contraria uma formação discursiva e ideológica segundo a qual são necessários somente os conhecimentos objetivados e hierarquizados do currículo prescritivo para garantir a qualidade da formação escolar e mostra a mudança de seu pensamento, já que antes se preocupava mais em "formar biólogos". Essa mudança parece ter sido desencadeada pela experiência de produção/veiculação das narrativas curriculares na disciplina no Mestrado.

Ao afirmar que passou a "olhar o aluno como pessoa", Clara desloca o próprio sentido do currículo, que passa de lista de conteúdos a serem cumpridos para construção dinâmica e permanente feita pelos sujeitos da educação (professores e alunos). A mestranda, em sua posição-sujeito professora, ressignifica o currículo como possibilidade constante de indagação e de reconhecimento de si e do outro. Assim, instaura o movimento de transposição da mera transmissão de conteúdos e técnicas para a percepção de que a ciência, o currículo e a atuação profissional docente são, em essência, atividades humanas. E devem estar, portanto, comprometidas não só com o individual, mas com o coletivo e o social. A partir das ponderações de Heidegger (2003) e Larrosa $(2002,2011)$ para o conceito de "experiência", é possível inferir que todo esse processo de produção e veiculação das narrativas digitais constituiu-se, para essa mestranda, como uma autêntica experiência narrativa e curricular pela qual ela ampliou seu capital narrativo (GOODSON, 2007a, 2007b) desenvolvendo-se-e questionando-se - como docente e como pessoa.

Mel também mostra ter feito movimentos de questionamento do currículo e de sua atuação como professora a partir da produção da narrativa digital:

Mel: A minha prática pedagógica mudou com as narrativas, porque eu comecei a aplicar as narrativas e ai eu tive que ter um olhar diferenciado sobre aquilo que eu estava transmitindo, sobre os conceitos que eu queria formar no meu aluno, que não eram só conceitos de Matemática, mas eram conceitos que ele tinha que ter pra vida dele. Então essa preocupação que eu tive de realmente estar formando o meu aluno na sua integridade, não só com conteúdo (grifos nossos). 
A mestranda, ao fazer referência a um "olhar diferenciado sobre aquilo que estava transmitindo" indica, pelo não dito (ORLANDI, 2013), que a transmissão de conteúdos ("conceitos de Matemática") constituía sua prática docente como elemento central. Com a experiência das narrativas digitais, assim como Clara, Mel passa a questionar o próprio sentido da mera transmissão dos conteúdos curriculares para a formação integral dos seus alunos. Uma formação articulada com o futuro social, com " $a$ vida" dos sujeitos (como enunciou a mestranda), porque extrapola os limites conteudistas e de transmissão bancária (FREIRE, 1987) para alcançar uma formação crítico-reflexiva que é, em última instância, o cerne da educação em suas possibilidades criativas e emancipatórias nos diversos contextos sociais e de trabalho. Esses movimentos indicam que Mel vivenciou uma aprendizagem narrativa (GOODSON, 2007a) cujos efeitos the permitiram pensar em novas maneiras de realizar o seu trabalho como docente na educação básica. A elaboração da narrativa digital permitiu a Mel parar e refletir; "[...] parar para sentir, sentir mais devagar" (LARROSA, 2002, p. 24). E se permitir vivenciar um processo de análise de trajetórias percorridas, de descobertas pessoais e profissionais e de tomada de decisões.

O movimento dialético de ir e vir entre a formação e a ação, entre o eu e o outro, entre as diferentes posições-sujeito que assumimos cotidianamente pode ampliar o capital narrativo dos sujeitos e ajudá-los a perceber outras formas de ensinar e de "ser professor(a)" - o que implica em uma aprendizagem narrativa capaz de "[...] fortalecer as faculdades críticas e autocríticas, desenvolvendo as capacidades dos indivíduos para definir e narrar propósitos de vida e missões em um ambiente de rápidas mudanças" (GOODSON, 2007a, p. 251).

O recorte discursivo de Cindy mostra indícios de uma aprendizagem narrativa que se amplia para outros tempos e espaços nesse movimento de crítica e autocrítica:

Cindy: Acho que narrar interfere na prática. Você começa a enxergar o aluno diferente, ouvir mais o aluno. As narrativas me deram essa leveza, essa suavidade mesmo (grifos nossos).

Cindy, assim como Clara, refere-se a começar a "enxergar o aluno diferente, ouvir mais o aluno" como um dos efeitos da produção e veiculação de sua narrativa digital como elemento curricular no mestrado. Esse discurso permite a produção de sentidos sobre o que seja esse "enxergar" associado ao "ouvir". Considerando as condições históricas ainda hoje constitutivas da maioria das práticas e dos currículos na educação brasileira, o discurso de Cindy parece trazer um não dito que afirma: "nossos alunos não são ouvidos/vistos na escola". 
As narrativas deram a Cindy a tranquilidade de "ouvir" e "enxergar" seus alunos sem culpa, com "leveza" e "suavidade"; talvez porque tenha experienciado (como mestranda) a construção de um currículo que se ergue pela ecologia de saberes (SANTOS, 2007; 2010a), de vozes, de conhecimentos, de experiências e interlocuções de todos e não sob o jugo de um único conhecimento considerado válido, imutável e inquestionável.

Em outro recorte discursivo, a mestranda sugere uma aprendizagem que diz respeito tanto a aprender com a narrativa quanto a aprender no ato da narração (GOODSON, 2007a, 2010). Cindy indica as funções reflexivo-integradoras das narrativas digitais de aprendizagem e seus efeitos na construção de um currículo narrativo na disciplina do mestrado:

Cindy: Quando chegou na disciplina de Práticas Docentes é que parece que tudo aquilo que eu vi [nas demais disciplina do mestrado] e que eu já vivi começou a fazer sentido. Porque eu tive que narrar aquilo e pude saber dos colegas, conhecer a história dos colegas. Então eu acho que as narrativas fizeram a gente se localizar: olha, vocês são professores, olha o que vocês estão vivendo, o que vocês já viveram, as dificuldades mesmo, as vitórias também (grifos nossos).

Ao enunciar que tanto os conteúdos curriculares quanto suas vivências como docente só "começaram a fazer sentido" com as narrativas curriculares, pela narração e pela leitura das narrativas dos colegas, Cindy indica um processo reflexivo de inter-relação entre o passado e o presente evidenciando também as funções integradoras e reflexivas das narrativas. Além disso, olhar o visto/ vivido como elemento do currículo pode deslocar a percepção dos sujeitos acerca da aprendizagem; já que vê-la "[...] como algo ligado à história de vida é entender que ela está situada em um contexto, e que também tem história [...]" (GOODSON, 2007a, p. 250). Essa interpretação parece corroborada pela percepção de Cindy sobre tudo aquilo começar a fazer sentido porque teve que narrar levando-a também a "se localizar" em suas aprendizagens e encontrar um lugar na cultura. Nesse movimento, feito pelos mestrandos e mestrandas, de localizar-se na/pela narrativa digital de aprendizagem, a temporalidade narrativa parece um elemento central e indica que a vivência do caráter tridimensional do tempo narrativo (RICOEUR, 1994) na construção e veiculação das narrativas digitais pode alterar os percursos curriculares dos sujeitos e o próprio currículo - que passa a constituir-se como um currículo narrativo capaz de gerar efeitos que extrapolam o espaço da formação e alcançam outros contextos, como os de atuação profissional dos sujeitos. 


\section{Considerações finais}

Este artigo se propôs a explorar a materialidade do conceito de currículo narrativo apresentando o uso de narrativas digitais de aprendizagem como uma das possibilidades de realização desse currículo em contextos educacionais. $\mathrm{Na}$ conclusão deste estudo, destacamos a importância de que as práticas curriculares abram espaços para que os sujeitos aprendentes desenvolvam o pensamento narrativo, pois é esse modo de pensamento que dá suporte ao currículo narrativo. Este, por sua vez, parece solicitar a ecologia de saberes, proposta por Santos (2007; 2010a), e pode, nesse sentido, contribuir para o reconhecimento e a produção da existência pelos sujeitos (SANTOS, 2004).

Além disso, podemos afirmar que as narrativas digitais de aprendizagem podem ser elementos para a construção do currículo narrativo na medida em que ampliam as formas pelas quais os sujeitos podem representar o pensamento narrativo por meio de diferentes linguagens em narrativas imagéticas multimodais, estruturar as histórias de seus percursos de aprendizagem e dialogar com o outro. Enquanto elementos curriculares, essas narrativas podem ser vistas como espaços promotores de uma aprendizagem mais dialógica e como possibilidades enriquecedoras tanto da temporalidade narrativa quanto da articulação crítico-reflexiva entre os conteúdos curriculares prescritivos e os conhecimentos, as experiências e o capital narrativo dos sujeitos - desde que haja espaços de compartilhamento e discussão a partir de versões parciais (o que é facilitado pela fluidez e acessibilidade das TDIC).

Compreendemos que a incorporação das narrativas digitais de aprendizagem às práticas curriculares na formação docente pode fazer emergir um processo formativo que viabiliza que os conhecimentos técnicos/tecnológicos aliem-se aos conhecimentos pedagógicos e à experiência do sujeito em formação costurados pela via da narrativa, numa escritura de si que leva ao movimento de ação-reflexão-ação na construção permanente de um currículo narrativo. Além disso, integra-se, pelas narrativas digitais (dinâmicas, mais facilmente editáveis e dialógicas) elementos da própria formação do sujeito como professor em conexão com sua experiência docente e discente expressa em narrativas comentadas e, de certa forma, coconstruídas no grupo a cada nova versão compartilhada, aliando a teoria e com a prática autêntica do mestrando/professor. Finalmente, destacamos a utilização de plataformas multimidiáticas (como as das redes sociais) como recurso carregado de potencialidades formativas e educacionais que vão desde a fluência tecnológica e os multiletramentos até a formação de 
sujeitos mais autônomos e com posturas mais autorais e reflexivas diante do mundo em que vivem. Salientamos também as limitações deste estudo quanto ao público e ao contexto investigados, e, com isso, indicamos a abertura a novas possibilidades investigativas que promovam o aprofundamento das discussões acerca das narrativas digitais como recursos tecnológicos e curriculares capazes de contribuir para a construção de currículos narrativos em outros espaços e com outros públicos considerando a cultura digital em que estamos inseridos.

\section{REFERÊNCIAS}

ALMEIDA, Maria Elizabeth Bianconcini de. Integração currículo e Tecnologias de Informação e Comunicação: Web currículo e formação de professores. (Tese de LivreDocência) - Faculdade de Educação, Pontifícia Universidade Católica de São Paulo, São Paulo, 2019.

ALMEIDA, Maria Elizabeth Bianconcini de; VALENTE, José Armando. Integração currículo e tecnologias e a produção de narrativas digitais. Currículo sem fronteiras, [s.l.], v. 12, n. 3, p. 57-82, set./dez. 2012. Disponível em: ttp://www.curriculosemfronteiras. org/vol12iss3articles/almeida-valente.pdf. Acesso em: 12 abr. 2020.

BRANDÃO, Helena Hathsue Nagamine. Introdução à Análise do Discurso. 3. ed. rev. Campinas: Editora da Unicamp, 2012.

BRUNER, Jerome. Life as Narrative. Social Research, [s.l.], v. 71, n. 3, p. 691-710, fall 2004. Disponível em: http://ewasteschools.pbworks.com/f/Bruner_J_LifeAsNarrative. pdf. Acesso em: 01 abr. 2018.

BRUNER, Jerome. A cultura da educação. Porto Alegre: Artmed, 2001.

BRUNER, Jerome. Realidade mental, mundos possiveis. Porto Alegre: Artes Médicas, 1997.

FREIRE, Paulo. Pedagogia do oprimido. 24. ed. São Paulo: Paz e Terra, 1987.

FREIRE, Paulo. Pedagogia da autonomia: saberes necessários à prática educativa. 34 . ed. São Paulo: Paz e Terra, 1996.

GATTI, Bernadete Angelina. Grupo focal na pesquisa em ciências sociais e humanas. Brasília: Liber Livro, 2012.

GOODSON, Ivor. Developing life and work histories of teachers. In: ABRAHÃO, Maria Helena Menna Barreto (org.). A aventura (auto)biográfica: teoria e empiria. Porto Alegre: EDIPUCRS, 2004. p. 243-2308. 
GOODSON, Ivor. Currículo, narrativa e futuro social. Revista Brasileira de Educação, Rio de Janeiro, v. 12, p. 241-252, mai/ago. 2007a.

GOODSON, Ivor. Políticas do conhecimento: vida e trabalho docente entre saberes e instituições. Tradução de Raimundo Martins e Irene Tourinho (org.). Goiânia: Cegraf, 2007b.

GOODSON, Ivor F. Towards a Theory of Narrative Learning. En: GOODSON, Ivor F. et al. (org.). Narrative Learning. United Kingdom: Routledge, 2010. p. 1-10. E-book. Disponível em: http://www.ivorgoodson.com/towards-a-theory-of-narrativelearning\#narrative-learning. Acesso em: $20 \mathrm{dez} .2017$.

GOODSON, Ivor. Dar voz ao professor: as histórias de vida dos professores e seu desenvolvimento profissional. In: NÓVOA, Antonio (org.). Vidas de Professores. 2. ed. Portugal: Porto Editora, 2013a. p. 11-30.

GOODSON, Ivor. Currículo: teoria e história. 14. ed. Petrópolis/RJ: Vozes, 2013b.

HEIDEGGER, Martin. A caminho da linguagem. Tradução de Marcia Sá Cavalcanti Schulback. Petrópolis, RJ: Vozes; Bragança Paulista: Ed. Universitária São Francisco, 2003.

LARROSA, Jorge. Experiência e alteridade em Educação. Revista Reflexão e Ação, Santa Cruz do Sul, v. 19, n. 2, p. 04-27, jul./dez. 2011. Disponível em: https://online. unisc.br/seer/index.php/reflex/article/download/2444/1898. Acesso em: 04 set. 2017.

LARROSA, Jorge. Notas sobre a experiência e o saber da experiência. Revista Brasileira de Educação, Rio de Janeiro, n. 19, p. 20-28, jan./abr. 2002. Disponível em: http://www. scielo.br/scielo.php?script=sci_arttext\&pid=S1413-24782002000100003\&lng=pt\&nrm =iso. Acesso em: 02 set. 2017.

MADDALENA, Tania Lucía; D’ÁVILA, Carina; SANTOS, Edméa. Visual storytelling e pesquisa-formação na cibercultura. Revista Brasileira de Pesquisa (Auto)Biográfica, Salvador, v. 3, n. 7, p. 209-305, jan./abr. 2018.

MAINGUENEAU, Dominique. Discurso e análise do discurso. Tradução de Sírio Possenti. São Paulo: Parábola, 2015.

MAINGUENEAU, Dominique. Discurso e análise do discurso. In: SIGNORINI, Inês (org.). [Re]discutir texto, gênero e discurso. São Paulo: Parábola, 2008. p. 135-156.

MARTINO, Luís Mauro de Sá. Teoria das Mídias Digitais: linguagens, ambientes, redes. 2. ed. Petrópolis, RJ: Vozes, 2015.

ORLANDI, Eni Puccinelli. Análise de discurso: princípios e procedimentos. Campinas, SP: Pontes, 2013.

PÊCHEUX, Michel. Análise automática do discurso (AAD-69). In: GADET, Françoise; HAK, Tony (org.). Por uma análise automática do discurso: uma introdução à obra de Michel Pêcheux. 4. ed. Campinas, SP: Editora da Unicamp, 2010. p. 59-158. 
RICOEUR, Paul. Tempo e Narrativa (Tomo I). Tradução de Constança M. Cesar. Campinas, SP: Papirus, 1994.

RODRIGUES, Alessandra. Narrativas digitais, autoria e currículo na formação de professores mediada pelas tecnologias: uma narrativa-tese. 2017. $274 \mathrm{f}$. Tese (Doutorado em Educação: Currículo) - Pontifícia Universidade Católica de São Paulo, São Paulo, 2017. Disponível em: https://sapientia.pucsp.br/handle/handle/20196. Acesso em: 25 maio 2018.

RODRIGUES, Alessandra. O potencial das narrativas digitais na aproximação/ apropriação da tecnologia: reflexões sobre dois contextos de formação de professores. Revista Observatório, Palmas, v. 5, n. 1, jan. 2019a. Disponível em: Disponível em: https://sistemas.uft.edu.br/periodicos/index.php/observatorio/article/view/4746. Acesso em: 11 set. 2019.

RODRIGUES, Alessandra. A autoria e a narrativa digital na formação de professores de Ciências mediada pelas tecnologias: entrelaçando possibilidades pela escritura de si. Revista Educação e Cultura Contemporânea, Rio de Janeiro, v. 16, n. 43, p. 276-304, 2019b. Disponível em: http://periodicos.estacio.br/index.php/reeduc/article/ view/5423/47965994. Acesso em: 12 set. 2019.

RODRIGUES, Alessandra. Mídias, efeitos de sentido e práticas de leitura e escrita: o que nos contam as narrativas digitais? Leitura. Teoria \& Prática, Campinas, v. 37, p. 101-113, 2019c. Disponível em: https://tp.emnuvens.com.br/ltp/article/view/750/488. Acesso em: 17 jan. 2020.

RODRIGUES, Alessandra; ALMEIDA, Maria Elizabeth Bianconcini de. Narrativas digitais na educação e na formação de professores: uma revisão sistemática de literatura. Cadernos de Educação, Pelotas, n, 56, p. 107-130, 2017.

RODRIGUES, Alessandra; ALMEIDA, Maria Elizabeth Bianconcini de; VALENTE, José Armando. Currículo, narrativas e digitais e formação de professores: experiências da pós-graduação à escola. Revista Portuguesa de Educação, Minho, Portugal, v. 30, n. 1, p. 61-83, 2017. Disponível em: https://revistas.rcaap.pt/rpe/article/view/8871/9173. Acesso em: 29 ago. 2019.

SANTOS, Boaventura de Sousa. Renovar a teoria crítica e reinventar a emancipação social. São Paulo: Boitempo, 2007.

SANTOS, Boaventura de Sousa. Um discurso sobre as ciências. 7. ed. São Paulo: Cortez, 2010a.

SANTOS, Boaventura de Sousa. Para além do pensamento abissal: das linhas globais a uma ecologia de saberes. In: SANTOS, Boaventura de Sousa; MENESES, Maria Paula (org.). Epistemologias do Sul. São Paulo: Cortez, 2010b. p. 31-83. 
SANTOS, Vanessa Aparecida; RODRIGUES, Alessandra; REZENDE JUNIOR, Mikael Frank. Tenho um tablet, e agora?: a produção de narrativas digitais como estratégia na formação de professores de ciências. Alexandria, Florianópolis, v. 11, p. 31-55, 2018. Disponível em: https://periodicos.ufsc.br/index.php/alexandria/article/view/19825153.2018v11n2p31/37894. Acesso em: 17 jan. 2020.

Texto recebido em 17/05/2020.

Texto aprovado em 30/11/2020. 